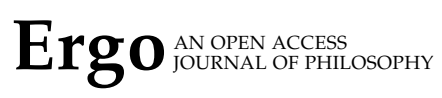

\title{
Multiculturalism, Autonomy, and Language Preservation
}

\author{
ETHAN NOWAK \\ University College London
}

\begin{abstract}
In this paper, I show how a novel treatment of speech acts can be combined with a well-known liberal argument for multiculturalism in a way that will justify claims about the preservation, protection, or accommodation of minority languages. The key to the paper is the claim that every language makes a distinctive range of speech acts possible, acts that cannot be realized by means of any other language. As a result, when a language disappears, so does a class of speech acts. If we accept that our social identities are in large part constituted by the decisions we make about how to speak, then language loss will amount to a substantial infringement on our autonomy in a particularly important domain.
\end{abstract}

\section{Introduction}

Many philosophers have offered arguments that aim to establish that the diversity of human cultures is important in one way or another. These philosophers claim that, other things being equal, we ought to celebrate and attempt to preserve cultural diversity, or at the very least, that it would not be wrong for us to do so. ${ }^{1}$ Many linguists and anthropologists, not to mention journalists and laypeople, have expressed the idea that the diversity of human languages is important in one way or another. They claim that, other things being equal, we ought to do what we can to prevent languages from becoming extinct, to document those that are beyond the point of viability, or at the very least, to lament the diminishing linguistic diversity that is a fact about our world. ${ }^{2}$

Contact: Ethan Nowak <e.nowak@ucl.ac.uk>

1. Compare Kymlicka (1989; 1995; 2001), Taylor (1994), Lovett (2010), Jeffers (2015), and many others.

2. See Day (1985), Sankoff (2001), and King and Haboud (2011) for a sample of academic work on language loss from different perspectives. Compare Crystal (2000), espe- 
Most of the prominent contributions to the philosophical literature on multiculturalism treat the relationship between culture and language as both broad and deep, and many of those contributions involve arguments that provide reasons for preserving, protecting, or accommodating minority languages. ${ }^{3}$ While some of those reasons are relevant where the phenomenon of language extinction is concerned, it is surprising how little dedicated attention the phenomenon has received, especially from philosophers working in what we might think of as very nearby areas. In the philosophy of language, for example, recent years have seen a substantial growth in research activity on questions of obvious social significance, like silencing, slurring, and conceptual engineering, but I am aware of no work that engages with the topic of language extinction directly. Similarly, the preservation of historical artifacts, objects of aesthetic significance, biological species, ecosystems, and much more has been the focus of major research in ethics, but similarities between these issues and the topic of language extinction, to the best of my knowledge, have not been explored.

My aim in the present paper will be to show how these diverse perspectives might be usefully drawn together to make progress on what I imagine most philosophers will agree is a substantial issue. Instead of attempting a broad survey of some of the various ways in which the existing literature on multiculturalism bears on the issue of language extinction, I will proceed by showing how a certain prominent kind of consideration that has been adduced in favor of multiculturalism, when interpreted in the light of some innovative recent work in the philosophy of language, might be used to justify claims about the preservation, protection, or accommodation of minority languages. 4

The kind of consideration I have in mind is due to Kymlicka (1995), who argues that cultures provide the agents that live within them the 'context of choice' that makes genuine autonomy possible. After quickly explaining how one tempting interpretation of Kymlicka's argument would fail to provide compelling reasons to care about language diversity, I move on to the positive proposal that forms the heart of the paper.

My key claim will be that every language makes a distinctive range of speech acts possible, speech acts that cannot be realized by means of any other language.

cially chapter two, for an overview written for a general audience, as well as Anthony Woodbury's 'Endangered Languages' for the Linguistic Society of America's outreach page at https://www.linguisticsociety.org/content/endangered-languages and Rachel Nuwer's 'Why we must save dying tongues' for the BBC at http://www.bbc.com/future/story/ 20140606-why-we-must-save-dying-languages for just a pair of representative popular press contributions.

3. Compare, for example, Taylor (1994), Patten (2001; 2005; 2009; in press), Kymlicka and Patten (2003), Levy (2003), Van Parijs (2000; 2003).

4. For an overview of ways in which the literature on multiculturalism connects with the phenomenon of language extinction, compare my Nowak (in press). 
One immediate result of this is that people who share a language share the ability to perform and recognize actions of a set of types that non-speakers cannot perform or recognize. I take this to reveal a sense in which speakers of a common language share a culture, and thus to reveal a sense in which the preservation, protection, or accommodation of a language would be the preservation, protection, or accommodation of a (part of a) culture.

The real significance of the claim that there are language-specific speech acts, however, is that it can be used to motivate a Kymlicka-style liberal defense of minority languages. In a nutshell, the argument runs as follows. Since language is the most fine-grained tool we have for making our inner lives public and for making our personalities manifest in a way that other agents can recognize and engage with, our social identities are in large part constituted by the decisions we make about how to speak. Those decisions, however, only have the significance they do when they are understood against the backdrop of the range of possibilities (the 'context of choice') our language makes available. So, there is an important sense in which self-determination depends on our having access to a community of others who speak our language. While I intend the piece to be taken as a first step rather than a final word, I hope it will go some way towards stimulating what I expect will be a productive area of common discussion between philosophers working in language, ethics, and politics.

\section{The Context of Choice and Linguistic Determinism}

In a series of influential contributions, Will Kymlicka has developed and defended an argument for multiculturalism that is rooted in the value of individual liberty. Although Kymlicka's strategy has attracted criticism from philosophers sympathetic to his conclusion but skeptical about his way of establishing it, as well as from philosophers who reject both the conclusion and the method, his approach constitutes one of the major lines of inquiry in a substantial literature. ${ }^{5}$

Kymlicka's basic idea is that people's ability to choose a conception of the good life and pursue that conception by living in a particular way depends on something he calls a 'societal culture':

A societal culture is an intergenerational community, more or less institutionally complete, occupying a given territory or homeland, sharing a distinct language and history. (Kymlicka 1995: 18)

In Kymlicka's view, societal cultures are important because they provide a 'context of choice', demarcating and shaping the space of possibilities within which an agent is able to select the course of her life:

5. Compare Waldron (1991), Okin (1999), Barry (2001), Kukathas (2001), Eisenberg (2003), Appiah (2005), Scheffler (2007), Patten (2009), and others. 
Liberals should recognize the importance of people's membership in their own societal culture because of the role it plays in enabling meaningful individual choice and in supporting self-identity. ... Cultural membership provides us with an intelligible context of choice, and a secure sense of identity and belonging that we call upon in confronting questions about personal values and projects. (Kymlicka 1995: 105)

The nature of the possibility space a societal culture makes available is determined partially by what we might think of as hard facts about the background time and place in which the culture is located, and partially by facts of a more obviously social character. So, for example, whether a societal culture makes commercial fishing a career possibility will depend on facts about geography and biology, as well as facts about economics and the prevailing views about fishing. Some cultures might revere fishers, others might afford them no special regard, still others might consider fishing a great evil. A person's choice of a career in fishing will thus amount to something different in different places-a societal culture, in other words, imbues a career choice (as well as choices about which hobbies, activities, association memberships, etc. to pursue) with the social significance it has:

People make choices about the social practices around them based on their beliefs about the value of these practices. ... To have a belief about the value of a practice is, in the first instance, a matter of understanding the meanings attached to it by our culture. (Kymlicka 1995: 83)

To really do Kymlicka's argument justice, much more would have to be said about autonomy and choice themselves, about which cultures should count as societal, which countervailing factors might tell against the accommodation, protection, or preservation of a particular culture, how the demands of multiculturalism should be weighed against other demands, and so on. For present purposes, however, we can set these considerations aside. Our aim is not to establish that Kymlicka's argument succeeds in showing that we should preserve, protect, or accommodate societal cultures, but to consider the extent to which an argument with the same basic structure-an argument based on liberal concerns about autonomy-might provide a reason for preserving, protecting, or accommodating languages.

Kymlicka himself frequently offers reasons for thinking that languages-at least in some cases-deserve to be taken seriously in some of the same ways that societal cultures do. Sometimes, those reasons are presented in explicitly instrumental terms:

The sort of solidarity essential for a welfare state requires that citizens have a strong sense of common identity and common membership, so 
that they will make sacrifices for each other, and this common identity is assumed to require (or at least be facilitated by) a common language and history. (Kymlicka 1995: 77)

It is not hard to see how this line of thinking might justify certain kinds of protections or support for minority languages, or indeed, for any language in need of such (and which was importantly implicated in the preservation of the social bonds that a societal culture depends on). If a common language is required to make people stick together in the way they must in order for a societal culture to persist, then insofar as we care about societal cultures, we have a reason to care about the languages those cultures depend on. ${ }^{6}$

Although the characterization of the psychological and sociological facts that this argument depends on seems plausible enough, my aim here is to show that deeper reasons can be given for thinking that languages might deserve protection, preservation, or accommodation. Since I am not concerned to establish that those deeper reasons are the only reasons in the vicinity, I will set aside questions about how far this kind of instrumental justification might be taken. ${ }^{7}$

Kymlicka frequently says things that might be taken to provide a more direct argument for preserving languages. Consider the following passage, for example, which draws substantially on some themes from Dworkin:

I noted earlier that societal cultures involve a 'shared vocabulary of tradition and convention' which underlies a full range of social practices and institutions (Dworkin 1985: 231). To understand the meaning of a social practice, therefore, requires understanding this 'shared vocabulary' - that is, understanding the language and history which constitute that vocabulary. Whether or not a course of action has any significance for us depends on whether, and how, our language renders vivid to us the point of that activity. And the way in which language renders vivid these activities is shaped by our history, our 'traditions and conventions'. Understanding these cultural narratives is a precondition of making intelligent judgements about how to lead our lives. In this sense, our culture not only provides options, it also 'provides the spectacles through which we identify experiences as valuable' (Dworkin 1985: 228). (Kymlicka 1995: 83)

On one natural way of reading this passage, it suggests a straightforward

6. This reasoning parallels an instrumental justification Kymlicka offers for the preservation of cultures themselves: "Cultures are valuable not in and of themselves, but because it is only through having access to a societal culture that people have access to a range of meaningful options" (Kymlicka 1995: 83).

7. It is worth mentioning, however, that if my primary argument is successful, the considerations I rely on will provide a new form of support for this kind of instrumental argument as well; the special capacities shared by members of a language community would provide a kind of explanation for the role a language plays in facilitating particularly strong social bonds. 
extension of Kymlicka's liberal argument for multiculturalism so that it covers language, too. If "understanding the meaning of a social practice" requires "understanding the language and history [which underlie it]", then the space of life possibilities we may choose between will be at least partially determined by the language we speak. Someone who did not speak our language would not be able to appreciate the social significance of the choices we make, and thus would not be faced with the same options as we are about what kind of life to live. ${ }^{8}$ To put the same point another way, if the space of possibilities that a culture makes available is (partially) constituted by a certain language, then insofar as we are motivated to preserve, protect, or accommodate the culture, we should be motivated to preserve, protect, or accommodate the language, too.

Call the foregoing the 'constitution argument'. An anonymous referee points out that it is not obvious that Kymlicka himself intended to endorse anything as strong as the constitution argument. In my own view, the most natural reading of Kymlicka is a reading on which he endorses quite a strong version of the argument. For our purposes, however, the exegetical question is less important than the question of what the constitution argument might show. Because the constitution argument is likely to occur to many readers-indeed, various formulations of it appear in nearly all popular writing on the subject of language extinction-and because the argument I will give in the next section might easily be confused with it, it will be worth taking a moment now to emphasize some problems the argument faces.

First of all, we can certainly accept that narratives and meaning-building are an indispensable part of the framework that makes choice possible without having to accept that the language spoken by a particular person or people has anything deep to do with the nature of the narratives in question, or with anyone's judgments about the significance of various courses of action. Of course, there is a sense in which understanding the significance of one's life choices requires understanding what Dworkin calls the 'vocabulary' of one's culture and traditions. 9 But treating 'vocabulary' in this connection as more than a metaphor, and thus defending the claim that the particular life choices a given culture makes available are in an important way shaped by features of a certain language would require substantial arguments of a sort that, to the best of my knowledge, none of the participants in this literature have attempted to provide.

It is also important to emphasize that we might perfectly well grant that understanding a narrative and making judgments requires having a language, or

8. To be clear: the problem here is not that a monolingual French speaker would find our conversation unintelligible, and thus fail to see what we are talking about. The idea is that even if the French speaker had access to translations of everything we say, those translations would leave out something essential to grasping the social significance of our decisions.

9. Taylor (1994) employs a similarly metaphorical characterization of the 'languages' of different forms of human activity. 
at least requires the kind of high-level and abstract thinking about potentially non-present people, objects, and situations that language is typically supposed to involve. This, however, is still a very far step from requiring a particular language or other, which is what would be required for the liberal defense of multiculturalism, as presented above, to generalize in a way that would support the preservation (etc.) of any individual language. ${ }^{10}$

The idea that the particular language we happen to speak shapes our experience of the world in a deep way has appeared periodically in modern academic literature in various guises since at least Whorf (1956). Although consensus in linguistics is as hard to come by as it is in philosophy, most linguists approach claims about what is often called 'linguistic determinism' skeptically, and those that accept a version of the view typically do so in a very attenuated fashion, in a very limited domain.

So, for example, while there is some controversy among linguists about whether the differences in the languages we speak might make some of us marginally better than others at re-identifying shades of certain colors, there is no mainstream support for the view that whether you can see red or not depends on whether your language has an analogue of the word 'red' in the lexicon. While some researchers have claimed that syntactic or lexical differences across languages produce measurable effects in people's ways of grouping certain objects or recalling certain sequences, the significance of these findings has typically been the topic of great dispute, and none of the putative evidence for determinism would support the kinds of striking claims Whorf made about languages such as Hopi and Coeur d'Alene, which he took to provide their speakers ways of thinking about time, space, causality, and so on that speakers of Indo-European languages could not readily access. ${ }^{11}$

Despite the wide variety of areas in which theses of linguistic determinism have been offered, I am aware of no linguist or philosopher of language who thinks that the grammar or lexicon of a particular language has a systematic

10. For further discussion of a related version of what is sometimes called the 'particularity' argument, see pages $321-323$ of the present article. To reframe the point from the body text in terms of the notion of 'narrative structure', it is clear that no one would be in a position to appreciate the narrative structure of Crime and Punishment if she did not speak a language. But it is just as clear that appreciating that structure does not require one to speak Russian-the arc of the story is framed by the relations that obtain between the contents that make it up, not the particular manner in which those contents are expressed in one language or another. This does not mean that nothing important about Crime and Punishment is lost when the book is rendered in a language other than Russian. Indeed, much of my argument will turn precisely on the sense in which I take it that something significant is lost-not the contents themselves or the structure they produce, but their mode of presentation. We will return to this point below.

11. For an excellent survey of both the history and the current state of play where linguistic determinism is concerned, see Gleitman and Papafragou (2005). For accessible discussion of the problems linguistic determinism faces, see Pinker (1994) and McWhorter (2014). 
impact on the evaluative judgments speakers of the language make. ${ }^{12}$ General antipathy to determinist theses probably has a lot to do with this. But there is a particular worry that would have to be met by anyone who wanted to defend the kind of far-reaching determinism about language that would be required to ground the constitution argument: what kind of evidence could they possibly rely on?

Suppose a certain language has a word for a certain kind of highly specific evaluative concept. The language is spoken only by people living in a certain culture, who make judgments about that concept frequently and consider them important. How should we determine whether the people in question have the word because they make the judgments, or whether they make the judgments because they have the word? Insofar as linguistic determinism has been accepted anywhere, it has been accepted precisely to the extent that it admits of empirical substantiation. But it is very difficult to imagine an experimental procedure that might reveal that the way a particular culture regards having a career in commercial fishing (say) is due to the structure of their language, as opposed to facts about their location in economic, geographic, cultural, and biological space.

In summary, the heart of the constitution argument is the claim that languages have a basic role to play in shaping the life choices made available to the people that live in a particular culture. If this claim were correct, Kymlicka's liberal defense of multiculturalism would by itself amount to a defense of the value of at least some languages, too. State of the art thinking in both linguistics and the philosophy of language, however, makes this kind of linguistic determinism look decidedly unappealing. If we want to apply Kymlicka's liberal argument to the case of minority languages, then, we will have to look for a different approach.

\section{The Outline of a New Liberal Argument for Language Preservation}

Kymlicka himself points out a passage from Dworkin that hints at one way his general argumentative strategy might be adapted:

People need a common culture and particularly a common language even to have personalities, and culture and language are social phenomena. We can only have the thoughts, and ambitions, and convictions that are possible within the vocabulary that language and culture provide, so we are all, in a patent and deep way, the creatures of the community as a whole. (Dworkin 1989: 488)

In this passage, something that seems to involve an appeal to linguistic

12. An anonymous reviewer, however, points out that Peled and Bonotti (2016) have recently approached the topic in political theory, and classic work in the vein of, e.g., Lakoff $(1987 ; 2003)$ might be read along these lines, as well. 
determinism of the form just argued against—-the claim that "we can only have the thoughts, ambitions, and convictions that are possible within the vocabulary that language and culture provide"-is accompanied by two strands of an importantly different line of reasoning. The first involves the idea that "we are all, in a patent and deep way, the creatures of the community as a whole" and the second the notion that we require "a common language even to have personalities".

Taken in one way, the idea that a person must share a language with other people in order to have a personality is clearly false. Pre-linguistic children and non-linguistic adults have personalities, and most pet owners would presumably say the same about animals. If we read Dworkin's claim about the connection between having a language and having a personality in light of the observation that we are "in a patent and deep way, the creatures of the community as a whole", however, we can appreciate another sense of 'personality', a sense in which the claim seems both more obviously correct and also more illuminating. Forget about whether you need to be the master of a language in order to come to have the outlook and dispositional tendencies that we normally think of as being part of your personality. Clearly there is a sense in which you have to have access to a public language in order to make your outlook and dispositions manifest to those around you, or at least, to make them manifest in their full richness and splendor.

If you travel to a foreign country where you do not speak the local language, you may be able to get others to see that you are patient or impatient, generous or not generous, but all of the fineness of grain that colors your interactions with people in your mother tongue is lost. Your wit, your tenderness, and your grace depend on the words you choose as much as they do on your underlying dispositions where non-linguistic behavior is concerned. There is a sense of 'personality', in other words, that is inherently social and that requires not just that you be a certain way, but that others recognize you as so being. ${ }^{13}$

The aim of the rest of the paper will be to show how we can turn this observation into an argument that establishes that having access to a community of speakers of your native language is a primary good. To preview, the argument will go like this. The choices we make about how to speak play a fundamental role in constituting our identities, a role comparable in significance to the role played by the choices we make about how to live. This is because we are social creatures, and the choices we make about how to speak are choices that the people around us take to reflect who we are. The choices we face about how to speak, however, are choices that are shaped by the particular nature of the linguistic environment we inhabit; different languages make different ranges of speech acts possible. So, people who are cut off from a certain linguistic community are thus deprived of the ability to realize a range of actions they would otherwise have

13. Variations on this theme appear in Taylor (1994) and Appiah (2005), among many others.

Ergo • vol. 6, no. $11 \cdot 2019$ 
been able to realize, and thus deprived of the ability to present themselves-and to be recognized as having done such-in certain ways. This gives us a reason to seriously consider the measures we might take to guarantee that people are not cut off from their linguistic communities.

\section{Language-Specific Speech Acts}

The first step of the argument will be to establish that there are speech acts that can only be realized in a particular language. To do that, it will be useful to remember the basic outlines of the philosophical tradition descended from Austin (1962) and Searle (1975), according to which speech acts can be characterized in terms of their illocutionary force and their content. The force/content distinction is meant to reveal both that which is similar across examples like the following, and that which is different:

(1) The door is closed.

(2) Is the door closed?

(3) Close the door!

Each of (1)-(3) share what in terms of the traditional taxonomy is called a content: the proposition that is at issue, that is, the proposition that the door is closed. What differs across the examples is the illocutionary force with which that content is expressed-in the first example the content is asserted, in the second example it is queried, and in the third it is commanded.

The force/content distinction has proven to be descriptively useful in a number of ways. For example, at least at a high level of generality, the distinction makes it easy to recognize a sense in which a variety of languages make the same basic types of speech act possible. Consider the following, for example:

(4) La porte est fermée.

(5) Est-elle fermée la porte?

(6) Fermez la porte!

According to the traditional story, since the French sentences (4)-(6) involve the same force and content as (1)-(3), they can be used to perform speech acts of the same general type as their English counterparts.

Despite the utility of the force/content distinction, however, there are explanatory projects for which a finer-grained characterization of speech acts is required. To really understand what a person does with her words often requires attending to very subtle choices she makes about how to deploy them. In addition to the force and the content that characterize a certain speech act, fully competent speakers of a language track a wide range of other features of the words and 
syntactic structures that are used to realize it, features that we might together think of as determining its mode of realization. ${ }^{14}$

\section{Conventional Devices}

The modal properties of a speech act (in the sense of 'mode of realization') depend on a wide variety of properties that characterize the words and structures used to realize that act. Sometimes, the words and structures involved conventionally encode information that determines the mode of realization. One kind of information that is frequently encoded concerns the level of politeness. Any competent speaker of English will recognize that there are important differences between the following (and endless variations thereupon):

(7) You done with the salt?

(8) Pardon me, but have you finished with the salt?

(9) Would you mind passing the salt this way when you have finished with it?

Each of (7)-(9) has the force of a request. But there is a level of description at which the speech acts that would normally be realized by means of these sentences are importantly different. Directed towards Grandmother, (7) may be insulting, while (9) will not be. Directed towards a colleague, (9) may come off as obsequious, while (8) will not. While it would be a mistake to identify a speech act with its effects, these differences in effect are nevertheless the result of differences in the mode of realization of the speech acts in question.

Of course, English is not unique in allowing speakers to select an appropriate (or inappropriate, as the case may be) level of politeness. Anyone who speaks basic French will recognize the difference between:

(10) Passe-moi le sel.

(11) Passez-moi le sel.

(12) Auriez-vous la gentillesse de bien vouloir me passer le sel?

In French, as in English, there are forms of words that are generally recognized to be more polite and forms of words that are generally recognized to be less polite. So in French, as in English, the range of speech acts that can be realized where a certain content is concerned is not limited to, for example, asserting, querying, or commanding (or any other type at this level of description). Each of those actions can be realized politely or impolitely, or indeed, at any of a wide variety of points on a (presumably multidimensional and messy) scale of politeness.

14. I offer a more detailed characterization of mode in Nowak (2018). There are important similarities between what I call the mode of realization of a speech act and the notion of register developed in Díaz-Legaspe, Stainton, and Liu (in press). 
Although given a token French utterance, it will presumably be possible in most cases to choose an English utterance that would capture a roughly equivalent level of politeness, there is an important difference between the two languages that deserves attention. In French, unlike in English, at least some information about politeness is explicitly encoded in the lexicon (tu/vous) and in the verbal morphology (-e/-ez verb endings).

Other languages explicitly mark similar distinctions at an even higher level of resolution. One of the difficult things about Korean for speakers of European languages is that Korean verb endings, instead of marking person or number, mark politeness relationships between the speaker and the addressee, and also between the speaker and the people about whom she is speaking (if she is speaking about a third party). The system of endings is very complex, involving perhaps 7 or 9 possibilities depending on how you count. While there is a 'standard' ending, choosing it remains a significant choice where the level of politeness expressed is concerned.

In keeping with my previously expressed skepticism about linguistic determinism, I should be clear that I do not mean to suggest that French and Korean speakers sort their interlocutors into categories of respect in a more fine-grained way than English speakers do. ${ }^{15}$ Nevertheless, there is something important that Korean speakers can do-and French speakers to a lesser extent-that English speakers cannot. They can employ a conventional device that their language makes available for the express purpose of situating themselves vis-a-vis their interlocutors. Where the level of politeness is concerned, they can (and indeed, must) haul up a flag, as it were, that is available to every speaker of the language and immediately recognizable by every speaker of the language.

As Stainton (2016) convincingly argues, and as is brought out nicely in DíazLegaspe et al. (2019), the fact that a certain linguistic operation is conventionalized in a language allows people to use it to do things with it that were previously not possible. Here is an example from Pushkin's 1828 poem Ty $i v y$, reprinted in Pushkin (1828/1959), that underscores the significance of this point:

Пустое вы сердечным ты

Она, обмолвясь, заменила

И все счастливые мечты

В душе влюбленной возбудила.

Пред ней задумчиво стою,

Свести очей с нее нет силы;

И говорю ей: как вы милы!

15. Whether they do this or not is an empirical psychological and anthropological question about which I do not speculate. If native speakers of Korean did sort people using more categories, it would be a stretch to claim that this sorting would owe its shape to the nature of the language they speak. 
Although the poem is well-known to Russian audiences, it is not typically included in collections of Pushkin's verse that appear in English translation. This is likely at least in part due to the fact that the entire poem is built around the scaffolding of a transition between the formal and informal second person forms of address that cannot be conventionally paralleled in English. ${ }^{16}$ In the first line, the lyrical subject's object of affection (allegedly unwittingly) slips from the 'empty' formal form of address to the 'heartfelt' informal. In so doing, she provokes an emotional transition in the lyrical subject, awakening a rush of feelings that are reflected back in the form of a parallel transition between forms, one that the lyrical subject makes public, and one that is kept private.

In English translation, the poem is usually called Thee and you, and is sometimes accompanied by a note that reminds readers that archaic English distinguished the formal 'you' from the informal 'thee'. When read in light of that note, English readers can sort of vaguely see how the structure is meant to work. But this is like the sense in which it is possible to appreciate why a joke that you have failed to understand the first time around would have been funny if you had understood properly. That is not the sense tellers of jokes are after when they tell jokes, and it is not the sense a poet or a translator would aim for, given the choice. The gap between the effect the modern English reader understands is meant to be felt and the effect that is in fact produced by the alternation between 'you' and 'thee' is presumably what leads translators to fill the final lines with additions like those reproduced below:

The pale "you are" by warm "thou art"

Through careless slip of tongue replacing

She sent within the love-struck heart

All sorts of happy fancies racing.

I stand before her all beguiled;

I stare at her, and the old Adam

Blurts out: You are all kindness, Madam!

And thinks: God, how I love thee, child!

(Pushkin 1828/1999: 75)

While the following French translation is clearly no substitute for Pushkin's original, it is worth including here for the sake of comparison:

Elle a remplacé ce "vous" convenu

En laissant échapper un cordial " $t u$ ",

16. It is important to note that the same technique occurs in other work of Pushkin's, work of more obviously substantial aesthetic significance. In Nowak (2018), I discuss a similar case drawn from Evgenii Onegin. 
Et éveillé en mon cœur amoureux

Par ce mot les rêves les plus heureux.

Quand pensivement je suis auprès d'elle,

Je ne puis détacher les yeux de celle

A qui je dis: votre air est si charmant!

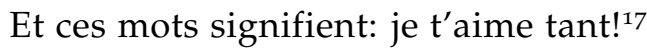

Instead of some nonsense about Adam and an infelicitous contrast between 'Madam' and 'child', the French translator can employ a binary distinction between forms of address that French readers cannot fail to notice, a distinction that is similar to the Russian distinction. The French translator, in other words, can do something with her words-slip from vous to $t u$-and invite the reader be a witness to that doing, instead of having to explain to the reader in parenthetical notes what the Russian original does.

This textual example shows how a speaker can exploit the difference between formal and informal second person forms of address in order to achieve a certain purpose. The point the example illustrates, however, is a perfectly general one: languages differ tremendously in terms of the range of conventional tools they make available, and they differ in terms of the properties and relations those tools track. Since these differences amount to differences in the space amount to differences in the space of possible modes of action, this means that different languages make different speech acts possible.

\section{History of Past Use}

Recent work on slurring and pejoration brings out another important way in which many of the speech acts that are possible in a language depend on highly particular facts about that language. One answer to the question about what makes slurs offensive that has attracted significant attention recently is: their history of past use. Lepore and Stone (2018) and Nunberg (2018), for example, claim that to be a fully competent user of a slurring expression you have to know not just that the word is a slur, or know how offensive a slur it is compared to others, but furthermore know something about the particular historical circumstances from which the slur's contemporary use descends. ${ }^{18}$

For Lepore and Stone, the offensiveness of the anti-Semitic slur 'kike', for example, is bound up with historical facts about anti-Semitism. The history of anti-Semitic prejudice is probably long enough and vile enough to guarantee that 'kike' would be a slur, even if the events of the Holocaust had never taken place. The fact that the Holocaust did occur, however, is implicated in making speech

17. Unattributed translation retrieved from https://akyla.net/stihi-na-francuzskom/ alexandre-pouchkine/373-alexandre-pouchkine/9257-tu-et-vous-ty-i-vy.

18. Elements of this line can be found in Anderson and Lepore (2013) as well. 
acts realized by means of that expression the speech acts they are. In Lepore and Stone's terms, the 'tone' of the expression 'kike', as used today, reflects the history of systematic anti-Semitic violence from the middle of the 2oth century; people who use the expression activate that history, and people who encounter the expression recognize as much.

Nunberg, along similar lines, says that "by affiliating himself with the historical owners of [a slur], the speaker doesn't simply evoke the word's background but materially obtrudes it into the context" (2018: 62). He illustrates the point with the following passage from Langston Hughes's 1940 autobiography:

The word nigger sums up for us who are colored all the bitter years of insult and struggle in America: the slave-beatings of yesterday, the lynchings of today, the Jim Crow cars, the only movie show in town with its sign up FOR WHITES ONLY, the restaurants where you may not eat, the jobs you may not have, the unions you cannot join. The word nigger in the mouths of little white boys at school, the word nigger in the mouth of the foreman at the job, the word nigger across the whole face of America!

Without taking a position on whether this is the best treatment of slurring, or whether this account should be accepted at the expense of other alternatives, it is hard to deny that there is something importantly right about it. ${ }^{19}$ If $A$ uses the n-word to denigrate $B, A$ does not simply denigrate $B$, or even denigrate $B$ in virtue of the way $A$ takes $B$ to be racialized. A denigrates $B$ with a word known to fully-competent speakers of A and B's community to have been used by people who advocated and implemented slavery, lynching, racially-motivated murder, and so on. There is a clear sense in which someone who is unaware of the history of the word fails to understand what people do when they use it.

The particular speech act possibilities made available by slurring expressions provide a powerful illustration of another point that is perfectly general: what we can do with our words often depends on highly particular facts about their histories. The point of the example is not to show that slurring is a valuable form of speech that might deserve protection, but to provide a particularly vivid illustration of the way in which the history of an expression shapes the space of speech act possibilities the expression makes possible. ${ }^{20}$ So, for example, anyone who says 'bigly' in 2018, to use Nunberg's apt locution, "materially obtrudes" Donald Trump into the context, whether the speech act involved is ironic satire or

19. For alternative accounts compare Potts (2007), Hom (2008), Richard (2008), Jeshion (2013), DiFranco (2015), and others.

20. Thanks to an anonymous referee for emphasizing the need to be clear about this. The referee's comment led me to see a potential connection between slurring, however, and a linguistic phenomenon that might indeed prove valuable: reclamation. I hope in future work to be able to explore the phenomenon of reclamation through the lens of the approach to speech acts and social identity that I have sketched here. 
loving imitation. Facts about the distribution of uses of 'bigly' are now, for better or for worse, facts about English, and we can leverage mutual knowledge of them to do things when we speak that we previously could not have done.

\section{Feature Overlap}

Before moving on to consider what the upshot of these considerations should be, it will be worth taking a look at one more class of examples, in order to see how the possible courses of action that a word or other linguistic element makes available typically depend not just on a single feature of the sort we have looked at so far-like conventional status, or history-but on the particular way in which a large number of those features happen to overlap. This fact makes the cross-linguistic variation in possible speech acts much greater than it would otherwise be.

Here is a case Lepore and Stone mention, but do not discuss in detail. Andrew O'Hehir, writing for Salon.com on November 17, 2015, offers the following take on the word 'niggardly':

Should we stop using the adjective "niggardly," because it accidentally resembles another word?

That one is instructive, in a way. Along with roughly 1oo percent of the media, I thought that controversy was ludicrous when it came up in the late '9os and early 200os: If we consult the dictionary, we learn that "niggardly" can be traced back to Middle English and Old Norse, and has no etymological connection to the racial slur. But I have to say that my perspective has since shifted. We pretty much have dumped that word, because it is so easily misunderstood and other words will do, and also because it carries a permanent taint: The only person who would conceivably use it now would be a snickering, anti-p.c. asshole trying to make an obnoxious point.

Suppose you are watching a televised debate with a friend who does not speak English. One of the parties to the debate, a nationalist candidate, uses the word 'niggardly' to describe his opponent's approach to veteran's affairs. You snort derisively. Your friend, who is reading along with subtitles, is surprised and asks why. While it might be right, at high level of generality, to say that the speaker has done something offensive, that response would not quite explain your reaction. Of course, in some contexts, derision might be an appropriate reaction to an offensive behavior-we might expect a certain level of decency from public figures, and take them to be worthy of scorn when they fail to live up to the expected standard by saying offensive things.

In this case, however, there is really more to the story. Speakers with the highest degree of competence in English will recognize not simply that the speech 
act realized was offensive, but that it was offensive in a highly particular way-in precisely the way a liberal listener would expect from a "snickering, anti-p.c. asshole trying to make an obnoxious point". ${ }^{21}$ In virtue of what do we recognize this? Your friend, surprised at the specificity of a description like this, might point out that the subtitles offered only 'My opponent's treatment of our veterans has been ungenerous', which seems perfectly neutral.

At some level of description, the translator has gotten things right. The speech act in question is an assertion. Its content is precisely the content reported by the translation. The translation misses out, however, on a constellation of properties that are tagged in the metadata associated with 'niggardly', metadata that fullycompetent speakers are familiar with, and which fully-competent speakers exploit when speaking and interpreting one another. O'Hehir does a good job tracking many of the relevant properties in the passage quoted above; one is that 'niggardly' is an extremely low frequency and antiquated expression, another is that it is phonetically uncomfortably similar to the n-word. More subtly, but no less importantly, there is the fact that we have other words in English that we can use to express the truth-conditional contribution 'niggardly' would express. ${ }^{22}$

Of course, contra the claims that might be made by defenders of the wilder forms of linguistic relativism, all of this information could be imparted to someone who did not know English. Sometimes, in fact, subtitles will feature explanations of jokes or innuendos that depend on phonetic features of the target language, or register facts, or that exploit other kinds of linguistic metadata. As was underscored in our discussion of poetry, however, explaining how something is done is a fundamentally different thing from actually doing it. In order to be offensive in exactly the way the politician who says 'niggardly' is offensive-to be offensive by deploying a word that looks and sounds like the n-word and is almost never used because of that fact, but which means what 'miserly' does-you

21. Importantly, I am not saying that the negative evaluation of the speaker on the part of the interpreter is entailed by the speech act in question. The nationalist candidate's supporters will detect in his speech a refreshing openness, a tweaking of the nose of the politically correct opposition. The important thing to notice here is that part of competence with English is knowing about the metadata associated with the lexical items and syntactic structures of English. So regardless of what you think of this act, you recognize the difference between it and the variation that would have been realized had 'niggardly' been replaced with 'miserly', or whatever. The liberal listener and the nationalist listener can disagree about whether the point is obnoxious or not, but they will both recognize that it involves a transgression.

22. It is important to be clear that the key idea here is that the identity of the speech act is determined by the precise set of overlapping features of various sorts associated with the words used to realize it. Many of those features will be tagged in the metadata, as facts about history, register, and so on are. But what we might think of as the basic facts about the content of the word are just as important. If 'niggardly' had meant what 'regally' means, the example might not work the way it does. The positive evaluative valence of 'regally' might defeat the invocation of the n-word. 
have to be speaking English.

\section{Interim Conclusion: Different Languages Make Different Speech Acts Possible}

To draw the threads that have been discussed so far in this section together, there are many reasons for thinking that facts about the manner in which a speech act is realized-facts that matter where the question 'what kind of speech act was this?' is concerned-are often facts that depend on the idiosyncrasies of a particular language. In other words, people exploit the particular architecture of the conventional devices their language makes available, together with mutuallyknown facts about the history of an expression, its similarity in sound, meaning, and other properties to other expressions, and so on, to do different things while speaking. While a translation of the expressions used in the original might preserve some of the features that made an act the act it was, there are many cases in which important properties of a piece of discourse-properties that help to determine which speech acts it might be used to realize-will not survive translation. While there may be an expression available in the language in which the translation is rendered that matches the original expression in terms of its content, say, or even content and register, there will not always be an expression that is a feature-for-feature analogue where the full range of features associated with an expression is concerned.

\section{The Importance of Language-Specific Speech Acts}

In the previous section, we saw that it is impossible for someone speaking English to do what a French speaker does by shifting from vous to $t u$ during a conversation. We saw that someone who is not speaking English cannot use the n-word to activate the historical background of violence and oppression that gives the word its status in English. ${ }^{23}$ And we saw how the speech act possibilities a language makes available typically depend not just on one, but on a constellation of features. These examples, and arbitrarily many others we could generate along the same lines, show that the particular nature of the language a person speaks plays a basic role in determining the space of possible speech acts that she can realize. To borrow Kymlicka's locution, the examples reveal a sense in which the language a person speaks provides her with a 'context of choice'. Not in Kymlicka's sense of the range of life plans presented to an agent, but in a more local sense that is nevertheless - as I will argue here-just as significant where our social identities are concerned.

23. Again, to be clear, the point here being not that this is a valuable thing to be able to do, but that slurs reflect how the speech acts a language makes available depend on its particular history. 
If French and English should disappear, speech acts that exploit particular constellations of features that obtain only in French or English would become unrealizable. If we want to show that the disappearance of a class of speech acts is problematic from the point of view of autonomy, however, we need a reason for thinking that it should be important that those speech acts in particular remain among the range of viable options available to some group of speakers.

The challenge here parallels a well-known objection to Kymlicka's liberal defense of multiculturalism: someone might accept that genuine autonomy requires the context of choice societal cultures provide, while denying that this amounts to a reason to preserve any particular culture or other. Individual agents might still count as properly autonomous, according to the objector, as long as they each had access to some societal culture or other, and thus to some suitably-varied set of alternatives about how to live. (Individual speakers would still count as properly autonomous, on the version of the argument that is at issue for us here, as long as they each had access to some language or other, and thus to some suitably-varied set of speech act alternatives.)

While a fully-detailed consideration of the ways in which the liberal multiculturalist might answer this worry would take us too far afield, there are two lines of response that are particularly well-connected with our current inquiry. The first essentially boils down to the claim that as a matter of psychological fact, adults cannot simply trade one culture for another. The second points out that for most people, elements of their heritage culture play such a fundamental role in contributing to their conception of themselves that they would not want to trade their culture for another even if they could. By adapting these two lines and weaving them together, we can make a compelling case for caring about the preservation of the particular range of speech acts a particular language makes available.

Patten (2009) describes a version of the 'change is too hard' argument that explicitly connects the questions of cultural and linguistic preservation. In order to avoid getting bogged down in questions of the sort Waldron (1991), Scheffler (2007), and others raise about how to delineate societal cultures (and how, thus, to tell which sets of practices might have a claim to protection), Patten suggests that the multiculturalist think of language as a sort of vehicle for accessing the range of life choices a certain culture makes available:

We might say that a language corresponds to a "societal culture" when a monolingual speaker of that language can find in her community an adequate context of choice. To say that there is a Francophone societal culture in Quebec, for instance, is to say that a French speaker in Quebec has access to an adequate range of options operating in the French language. To say that there is no Italian-speaking societal culture in the United States, by contrast, would be to deny that an Italian speaker in 
that context has an adequate range of Italian-language options. To enjoy personal autonomy, an Italian-speaker in the United States must learn English and access the English-language societal culture that dominates the country. (Patten 2009: 16-17)

If we accept Kymlicka's basic claim about the sense in which cultures make choices available, and if we think about language in the way Patten suggests, then the empirical facts about language acquisition may give us a reason to preserve languages:

If a person's societal culture is deteriorating, it may not be feasible for her to learn a new language associated with a healthier societal culture. For adults at least, learning new languages is a costly and difficult proposition, one for which success is not always guaranteed. In practice, the disintegration of a societal culture may leave some of its members without an adequate context of choice-just as Kymlicka argues. If minority language rights can prevent such disintegration from occurring-by raising the status of a minority language at risk-then there would seem to be a rationale for such rights that liberals should take seriously. (Patten 2009: 18)

The question of whether this strategy will ultimately be successful in any given case depends both on general facts about how hard it is for adults to learn a new language and on specific facts about the range of life options available to certain people in a certain place at a certain time. Where the general facts about language acquisition are concerned, my understanding of the situation on the ground is decidedly less pessimistic than Kymlicka or Patten's. If the standard of speaking a language is that of being able to participate in public life-as many of the contributors to this literature seem to hold-or of being able to avail oneself of a suitably wide range of the life options that are available in a certain place to those who speak the local language natively, then it seems to me that most normal adults will be able to meet that standard without unreasonable effort.

Instead of speculating further along these lines, however, I want to offer what I take to be a largely sympathetic way of recasting Patten and Kymlicka's argument. In my view, the 'change is too hard' argument can be made much stronger if we approach language proficiency from the perspective I have advocated in the present paper. Suppose that instead of thinking of the sphere of autonomy that we are concerned with as the sphere of possible ways that someone might choose to live her life, we think of it as the sphere of possible speech acts that is typically available to a speaker speaking her native language. If that is the level of proficiency required for someone to count as having 'switched' languages, then we have a much better reason to think that few people would be able to attain it. To speak a language well enough to run a business or work productively is-it seems 
to me-fairly easy. To speak a language fluently is harder. To speak a language totally idiomatically, to be able to deploy the full range of registers, intonations, colloquial references, and so on that native speakers employ, is something that adults are not frequently capable of.

Native speakers of a language, whether gifted orators or George W. Bush, nearly effortlessly manage a huge range of signals beyond those that contribute to the basic informational content associated with the words they use. By means of those signals, they do all sorts of subtle things, positioning themselves socially in various fine-grained ways, establishing and flouting hierarchies, seeking to build rapport and accepting or rejecting others' attempts, and so on. If we ask: 'Can most people learn a second language well enough to more or less live a free life?' then the answer, it seems to me is clearly 'yes' and so we find no obvious reason here to care about protecting their native language. If, on the other hand, the question we ask is: 'Can most people learn a second language well enough to have roughly the same facility a native speaker does in deploying the language with a full knowledge of all the shades and layers of significance that are wrapped up in the messages she is sending?' then the answer I think is much more clearly 'no'. ${ }^{24}$

This brings us to the second of the argument strands mentioned above. Kymlicka, drawing on Margalet and Raz (1990), cites the fundamental role cultures play in establishing a person's identity in order to show how switching cultures is not a live option for people whose culture is under threat:

Cultural membership has a 'high social profile', in the sense that it affects how others perceive us and respond to us, which in turn shapes our selfidentity. ... If a culture is not generally respected, then the dignity and self-respect of its members will also be threatened. (Kymlicka 1995: 89)

What Kymlicka says here about culture is true of language, as well, and perhaps even more substantially so. While it may well be the case that many people identify with the language they speak-in Taylor's (1994) sense of being proud to be speakers of that language, feeling a connection to other speakers, etc.- -there is a sense in which the language we speak has a 'high social profile' for us that, in my view, far outstrips the significance of our identity qua members of this or that language group.

As I said in Section 3, drawing on Kymlicka's invocation of Dworkin, it does not strike me as an exaggeration to say that the course we chart through speech-act

24. Language is an extremely powerful tool. Even a rudimentary grasp of a language allows you to do very important things. But it is a tool that really reaches its potential only in the hands of a master. When wondering whether someone can pick up a new language, we should not ask whether they can split logs with it, or even build a cabin, but whether they can carve in filigree. The answer, for most people, in most places, will be 'no'. 
space constitutes at least a substantial piece of our personality. Language, as I said before, is the finest-grained tool we have for making our inner selves public, and for viewing one another as agents who act for reasons, as displaying particular aesthetic proclivities, as being funny or clever or as being not funny or clever. Our public selves, the selves that our friends and family are acquainted with, are in large part the product of the linguistic choices we make. Our linguistic behavior does not just "affect how others perceive and respond to us". In a substantial sense, our linguistic choices constitute the us that others perceive and respond to. 25

Seeing language as the clay, as it were, from which our social identities are molded brings out how much is at stake here. Even if you could pick up a new lump-which, for the reasons given earlier in this section, most people cannot-you simply could not use it to mold the same thing as you can with this lump. Despite having total control over a second language, people who are fully bilingual cannot do all of the things in their second language that they can in their first (and vice-versa). This means that if one language should disappear, or if a speaker should be cut off from it, having access to another will not prevent their being cut off from a range of ways of expressing themselves, and thus being cut off from a range of ways of being. ${ }^{26}$

By the same token, if there were a way to take the measure of the dignity provided to a person by the language she speaks, it seems to me that the greater part would be due not to the fact of speaking this or that language (i.e., not to the simple fact of group membership), but to the way in which the language she speaks allows her the fullest possible control over how to present herself.

Anyone who speaks more than one language knows what it is to come across at different levels of resolution, to be more or less able to maneuver in precisely the desired way. If English were to disappear from the Earth next week, the problem for me, where my dignity and self-respect are concerned, would not be

25. The connections here with poetry here are clear and deep. In much the way the lyrical subject of a poem is literally constituted by the poem itself, a certain body of work constitutes the public persona associated with a poet. Consider a possible world in which Alexander Pushkin biologically survives a cataclysmic event that results in the Russian language's disappearing from the face of the earth in 1835. Does Pushkin, the person we know, survive the event? There seems to be an accessible sense of 'person' in which the answer is no; certainly he is not the same person as he was while the language was alive. He cannot there do the things that in our world make him who he is, as no one there can recognize his speech acts for what they are.

26. If Pushkin can serve as an example of how significant a role our linguistic choices play in making us who we are, we might take Nabokov as an example of the sense in which our identity does not survive translation. Nabokov probably knew English as well as any native speaker. The history of the autobiographical project realized over the course of Nabokov $(1951 ; 1954 ; 1966)$, however, reveals how acutely aware he was of the fact that his identity was distributed over two languages. He simply could not do the same things in each language, and thus, to speakers of the different languages, he appears as different people. 
that I could no longer fly the flag of the Anglophone world, but that I could no longer exert the kind of control I currently do about how others see me. When Vladimir Putin chooses to refrain from speaking English in public, it is not simply because he wishes to avoid making a symbolic concession to the West, it is because in speaking one's own language, one can be sure, or at least as sure as anyone ever is, about what exactly one is doing. Of course, there is a superficial form of dignity such control allows-the dignity of not accidentally doing something silly, like saying Either give us a suitcase, or we'll lick a lawyer when you meant to say Either give us a ticket, or we'll call a lawyer in Spanish. But there is a deeper dignity, too, the dignity of knowing yourself to be the master of a certain domain. This dignity is lost by people who never have the option of speaking their native language.

\section{Objections and Discussion}

If the argument from the previous two sections is successful, it offers a so far unappreciated reason for caring about language extinction: when a language disappears, the last speakers lose access to a range of previously possible speech acts. Since I have argued that autonomy with regard to the speech acts we realize amounts to autonomy with regard to the social identities we construct for ourselves, I take this to be a substantial loss, and thus, a reason to care about preserving languages, as well.

Although there is no space here to defend any specific proposal about what kinds of language preservation measures might be warranted in which social or political contexts, or about how to weigh the value of the kind of autonomy I have described here against other forms of freedom or other basic goods, by considering two objections to the argument I have presented, I hope to make clear that we should take the kind of freedom I have described so far quite seriously, and thus to lay the foundation for future work exploring questions of implementation in greater detail.

The first objection, which we might call 'the caviar objection', is due to an anonymous referee. Simply put, the objection is this: while everyone might have a right to eat, no one has a right to eat caviar. Similarly, while everyone might have a right to expression, no one has the right to express herself with the full degree of subtlety that I claim is possible for most people only in their native language. To sharpen the objection, the referee points out that non-native speakers can publish academic books, participate in prestigious conferences, and even fall in love in their second or third languages. If someone can do all of this, why should we care about whether she is also able to select between the possible speech acts she realizes with the kind of extraordinary fineness of grain that we have described here? 
The general shape of my response to this objection can be captured by saying that where the objector sees black caviar, I see brown rice. Of course, I do not deny that the speech acts I have used as examples here are individuated with an extraordinary fineness of grain. As I have argued, people track a tremendous variety of information-bearing features when producing and interpreting speech-features that include the shape and sound of the expressions used, their truth-conditional contribution and their emotional shading, their history, their frequency, their prominent uses, and much more. The fact that we can effortlessly interweave these various features to create structures that are significant along multiple dimensions at once strikes me as thoroughly remarkable. It is important to be clear, however, that where 'extraordinary' means 'rare', there is nothing extraordinary about this at all.

While great speakers and writers stand out for their particular expressive gifts, the kind of very precise discriminating capacities I have tried to emphasize here are hardly confined to their ranks-on the contrary, such capacities form a piece of the basic inheritance that nearly every person acquires naturally as a native speaker of a language. What we might call 'polysemous speech' - speech that exploits multiple layers of significance at once-is not a frivolous extra, ${ }^{27}$ bolted on for decoration over the structures that allow us to perform the truly fundamental linguistic tasks like telling one another how many potatoes are left, or whether predators are nearby. Polysemous speech, and the fine-grained discriminatory capacities that underlie it are, as I see things, completely central pieces of our linguistic lives, and they allow us a degree of control over one of our central linguistic activities, that is, the structuring of our social relationships, that would otherwise be impossible.

Presumably no one will deny that it is possible to live a good life without living in a linguistic environment in which you are able to exert the degree of

27. I suspect that some of the apparent force behind the caviar objection is due to the fact that taken individually, each of the examples I have offered here of language-specific speech acts might seem frivolous. So, for example, it is hard to think that my expressive autonomy is undermined in an important way if changing circumstances make it impossible for me to continue to rhyme 'Trump' with 'chump' (say), or that a snickering jerk has grounds to demand redress if it should become impossible to use 'niggardly' to make the kind of obnoxious point described by $\mathrm{O}^{\prime}$ Hehir above on page 318 .

To concede that any one of the particular speech acts a certain language makes available could be given up without that sacrifice amounting to something of significance, however, is not to concede that the same holds of their sum. On the view I have described here, our public personalities are largely constituted by the decisions we make about how to navigate through the space of options our language makes available to us. Although I acknowledge that much more would have to be said about what a public personality is and how exactly the words we use contribute to shaping one, I hope the basic idea will be clear enough to make appreciable the kind of thing that is at stake. If you lose access to your native language, you lose access to all of the particularities and patterns of expression that make your voice what it is, and you thus lose access to a way of being you. 
control a native speaker does over how you present yourself to those around you. The standard of being able to live a good life, however, is not obviously the standard that should be applied in determining whether something involves a considerable sacrifice, or in determining whether people should be expected to agree to a social or political order that would require their doing it. If someone chooses to live in a second or third language, she chooses to have less control over the speech acts she realizes, and thus over her social identity, than nearly every human throughout history has had. ${ }^{28}$ If we require someone to live in a second or third language, we require them to have less control over the speech acts they realize, and thus over their social identity, than nearly every human throughout history has had.

A musical analogy can help to bring this point out in a way the comparison between rice and caviar does not. Imagine that every one of us is born with the musical gifts of a piano prodigy. We grow up in a community where everyone we know is constantly playing incredibly rich and expressive music, and in which the structure of our social relationships is substantially the product of those musical interactions. Now imagine that one day, someone takes your piano away and hands you a tin whistle. If you are lucky - and most of us, for what it is worth, are not-your inherent talent for the piano generalizes, and you quickly turn into a solid whistler. In this scenario, you might be able to do pretty well in interactions with pianists, but there is no question that you are condemned for the rest of your life to play in a much lower resolution than everyone else. The reduction in your space of expressive possibilities here seems especially lamentable given that you have this incredible piano music inside you, this latent expressive capability that now, no one can ever recognize. ${ }^{29}$

The second objection, which two referees raise versions of, concerns the question of how far the kinds of reasons for language preservation that I have argued for here are likely to extend in time. As one referee frames the objection, someone might grant that access to your native language is something that you have a fundamental interest in-based on the role your language plays in shaping your social identity—but deny that this provides any reason to think that your

28. By 'control over your social identity' here I mean just in the sense in which we shape our social personas by means of our words. There are other factors that contribute to the public identities we take on that I imagine for much of history were even further outside of most people's control than they are today, like factors involving racialization, class status, and so on.

29. Consider counterfactual Pushkin again. In a scenario in which Russian is set to disappear from the face of the Earth forever, surely it will be cold comfort for him to know that he will be able to continue to attend conferences and even fall in love with someone who speaks French. I think we are all more like Pushkin than the objector seems to. While our productions may not have the aesthetic value that his do, they are what make us who we are. Whether you want to be a stand-up comedian, or a journalist, or the local character down at the pub who tells a good story, or a grandparent with a wise folksy way, the way you talk is who you are. 
language should be preserved for future generations. Another referee illustrates the point with regard to a hypothetical case in which an Anglophone government moves to assimilate future Québécois by progressively moving future generations away from French and towards English. If the project is realized carefully enough, there will never be a person who finds herself without a native language, and thus, there will never be a person who could complain that her right to social self-determination with the adroitness of a native speaker has been infringed.

The first point to make in response to this objection is that even if we accept it at face value and concede that the considerations advanced here only apply to current and not future speakers of a language, it would leave the most substantial piece of the conclusion we have argued for here standing. The basic aim of the present paper is to show that it is useful to see language extinction as undercutting the autonomy of speakers of the languages that are threatened. The space of speech acts that we have access to when speaking our heritage language is a space that cannot be replicated in other languages, and indeed, the degree of control that we exert when speaking our heritage language is a degree that cannot generally be had when speaking a second language. I take it that this by itself provides a significant new kind of ground for claims about language protection and preservation.

As a matter of fact, however, it is difficult to imagine scenarios in which the interest current speakers have in being connected to their native speech communities could be protected in a way that will not also generate obligations that persist through time. Consider the scenario the referee describes above. Even if we set aside questions about whether there could be defensible reasons for implementing a curriculum expressly designed to assimilate a linguistic minority, it is hardly clear that the kids in this case will be ok as French fades and disappears. Of course, someone raised as a fully-bilingual speaker of French and English would be better off in a future society in which only English is spoken than a monolingual French speaker would be, or than an adult student of English as a second language. The bilingual person, after all, still has access to a linguistic community in which she counts as a fully-empowered member.

If these bilingual students are raised as native French speakers by Francophone parents, however, it seems likely that the kind of argument I have given here will go through for them, as well. There are things these students can do when speaking French that they cannot do when speaking English. If what I have said here about the role speech acts play in constituting a person's social identity is on roughly the right track, these people will end up with a substantial interest in preserving access to their Francophone communities. Without such access, they will be unable to be recognized, as it were, as the people they are. Since every generation will have a significant interest in sharing a native language with their children, and children an interest in sharing their parents' language, the kinds of 
claims to which linguistic identity gives rise are likely to endure through time..$^{30}$

\section{Conclusion}

In this paper, I have claimed that liberal concerns about the value of autonomy can be used to motivate an argument for language preservation. Instead of trying to show that an agent's language shapes her possible life paths, in the sense of Kymlicka's 'context of choice', I have recommended focusing our attention on a different space of possibilities: the space of possible speech acts an agent might realize. I argued that autonomy with regard to speech acts amounts to autonomy with regard to the social identities we construct for ourselves. Since different languages make different ranges of speech acts possible, insofar as we are concerned that people be free to choose their social identities, we should be concerned that they be free to speak (and be understood in) their native languages.

Of course, showing that we ought to take the question of language preservation seriously is not equivalent to showing that the government should open different schools to cater to people who speak different native languages. It does not mean that we should pay money to speakers of minority languages, or that we show more foreign language films, or support their production, or anything else. Questions about what concrete policies might be defensible on the basis of the kind of argument I have presented here are questions for another day, as are questions about how to weigh the value of the kind of autonomy I have described against other forms of freedom or other basic goods. Nevertheless, I hope this paper will go some way towards establishing a point that I think has not been made clearly in the literature so far: there is an important sense of freedom that depends on our access to a community within which we can determine the way we present ourselves in the way that only our native language allows us to do.

In keeping with the aim of highlighting areas in which more dialogue between philosophers working in language, ethics, and politics might be fruitful, I would like to close the paper by briefly pointing to some ways in which this project might be developed in the future. One of those, raised by an anonymous referee, concerns the extent to which the kinds of considerations offered here in support of claims about the preservation of languages might apply as well to claims about the significance of dialects or sub-dialects.

30. Of course, I do not mean that children everywhere do or even should care about learning their parents' languages (even if there might be a sense in which they have an interest in doing so), or that parents everywhere care that their children become native speakers of their languages. In many cases involving migration, a language will not be transmitted across generations. In many cases this may be, on balance, an acceptable outcome, even if there are reasons to think that something valuable would be preserved if the language involved endured among the people in question. 
While I think the point I have tried to press comes out most clearly in the case of languages, I suspect that much of what I have said will apply to, for example, regional dialects and the dialects associated with particular subcultures, as well. On the face of things, it seems plausible to think that speakers of a particular dialect will sometimes have access to speech act possibilities that speakers of other dialects do not. Depending on the position speakers of that dialect occupy within the broader society, it might turn out that the differences are differences that are especially significant where questions of social identity are concerned. So, the kind of argument given here might well offer reasons to care about preserving or protecting variations in linguistic practice even within a single language.

Even if we eventually decide that dialects, sub-dialects, or the particular argot spoken by a particular group at a particular time do not deserve the same kinds of protections that a language does, there might nevertheless turn out to be interesting social or political consequences that follow from recognizing the role the dialects play in allowing people to present themselves in a certain way. I alluded earlier to the value some theorists have found in the way marginalized groups reclaim slurring expressions used to target them; reclamation provides one model for how dialectical variation might be socially important. Recent work on multiculturalism offers other potentially relevant models, too. If, for example, as Jeffers has it, "projects of cultural preservation [can be] a form of resistance" (2015: 220) to colonialism, racism, and other forms of oppression, then so, perhaps, might speaking a particular language or dialect.

\section{Acknowledgements}

Although errors, oversights, and infelicities are mine alone, I am grateful to Simona Aimar, Nicholas Gooding, Rebecca Harrison, Matthew Kendall, Tienmu Ma, Michael Martin, Eliot Michaelson, Véronique Muñoz-Dardé, Robert Simpson, Robert Stainton, Kevin Toh, and two anonymous referees for extremely helpful comments and discussion. I would also like to thank the Ergo editors for their remarkable work managing the journal, and Robert Mason for substantial technical help and an eye for detail. Finally, I would like to acknowledge the particularly fundamental influence of Lyubov Golburt and Anna Muza, without whose patience and encouragement this work would not have been possible.

\section{References}

Anderson, Luvell and Ernest Lepore (2013). What Did You Call Me? Slurs as Prohibited Words. Analytic Philosophy, 54(3), 350-363.

Appiah, Kwame Anthony (2005). The Ethics of Identity. Princeton University Press. 
Austin, J. L. (1962). How to Do Things with Words. Harvard University Press.

Barry, Brian (2001). Culture and Equality: An Egalitarian Critique of Multiculturalism. Harvard University Press.

Crystal, David (2000). Language Death. Cambridge University Press.

Day, Richard R. (1985). The Ultimate Inequality: Linguistic Genocide. In Nessa Wolfson and Joan Manes (Eds.), Language of Inequality (163-182). Mouton.

Díaz-Legaspe, Justina, Robert Stainton, and Chang Liu (in press). Slurs and Register: A Case Study in Meaning Pluralism. Mind and Language.

DiFranco, Ralph (2015). Do Racists Speak Truly? On the Truth-Conditional Content of Slurs. Thought, 4(1), 28-37.

Dworkin, Ronald (1985). A Matter of Principle. Harvard University Press.

Dworkin, Ronald (1989). Liberal Community. California Law Review, 77(3), 479-504.

Eisenberg, Avigail (2003). Diversity and Equality: Three Approaches to Cultural and Sexual Difference. The Journal of Political Philosophy, 11(1), 41-64.

Gleitman, Lila and Anna Papafragou (2005). New Perspectives on Language and Thought. In Keith J. Holyoak and Robert G. Morrison (Eds.), Cambridge Handbook of Thinking and Reasoning (633-661). Oxford University Press.

Hom, Christopher (2008). The Semantics of Racial Epithets. Journal of Philosophy, 105(8), 416-440.

Hughes, Langston (1940). The Big Sea. A. A. Knopf.

Jeffers, Chike (2015). The Ethics and Politics of Cultural Preservation. Journal of Value Inquiry, 49(1-2), 205-220.

Jeshion, Robin (2013). Slurs and Stereotypes. Analytic Philosophy, 54(3), 314-329.

King, Kendall A. and Marleen Haboud (2011). International Migration and Quichua Language Shift in the Ecuadorian Andes. In Teresa L. McCarthy (Ed.), Ethnography and Language Policy (139-159). Routledge.

Kukathas, Chandran (2001). Is Feminism Bad for Multiculturalism? Public Affairs Quarterly, 15(2), 83-98.

Kymlicka, Will (1989). Liberalism, Community, and Culture. Oxford University Press.

Kymlicka, Will (1995). Multicultural Citizenship. Oxford University Press.

Kymlicka, Will (2001). Politics in the Vernacular: Nationalism, Multiculturalism, and Citizenship. Oxford University Press.

Kymlicka, Will and Alan Patten (2003). Language Rights and Political Theory. Annual Review of Applied Linguistics, 23, 3-21.

Lakoff, George (1987). Women, Fire, and Dangerous Things. University of Chicago Press.

Lakoff, George (2003). Metaphors We Live By. University of Chicago Press.

Lepore, Ernest and Matthew Stone (2018). Pejorative Tone. In David Sosa (Ed.), Bad Words: Philosophical Perspectives on Slurs (134-153). Oxford University Press. 
Levy, Jacob (2003). Language Rights, Literacy and the Modern State. In Will Kymlicka and Alan Patten (Eds.), Language Rights and Political Theory (230-249). Oxford University Press.

Lovett, Frank (2010). Cultural Accommodation and Domination. Political Theory, $38(2), 243-267$.

Margalet, Avishai and Joseph Raz (1990). National Self-Determination. Journal of Philosophy, 87(9), 491-510.

McWhorter, John (2014). The Language Hoax. Oxford University Press.

Nabokov, Vladimir (1951). Speak, Memory. Victor Gollancz.

Nabokov, Vladimir (1954). Drugie berega. Izdatel'stvo imeni Chekhova.

Nabokov, Vladimir (1966). Speak, Memory: An Autobiography Revisited. G. P. Putnam's Sons.

Nowak, Ethan (in press). Language Extinction. In Rachel Sterken and Justin Khoo (Eds.), The Routledge Handbook of Social and Political Philosophy of Language. Routledge.

Nowak, Ethan (2018). Language Loss and Illocutionary Silencing. Manuscript submitted for publication.

Nunberg, Geoffrey (2018). The Social Life of Slurs. In Daniel Fogal, Daniel Harris, and Matt Moss (Eds.), New Work on Speech Acts (239-291). Oxford University Press.

Okin, Susan Moller (1999). Is Multiculturalism Bad for Women? In Joshua Cohen, Matthew Howard, and Martha C. Nussbaum (Eds.), Is Multiculturalism Bad for Women? (7-24). Princeton University Press.

Patten, Alan (2001). Political Theory and Language Policy. Political Theory, 29(5), 691-715.

Patten, Alan (2005). The Rights of Internal Linguistic Minorities. In Avigail Eisenberg and Jeff Spinner-Halev (Eds.), Minorities within Minorities: Equality, Rights, and Diversity (135-154). Cambridge University Press.

Patten, Alan (2009). The Justification of Minority Language Rights. The Journal of Political Philosophy, 17(1), 102-128.

Patten, Alan (in press). Protecting Vulnerable Languages: The Public Good Argument. In David Sobel, Peter Vallentyne, and Steven Wall (Eds.), Oxford Studies in Political Philosophy (Vol. 5). Oxford University Press.

Peled, Yael and Matteo Bonotti (2016). Tongue-Tied: Rawls, Political Philosophy, and Metalinguistic Awareness. American Political Science Review, 110(4), 798811 .

Pinker, Steven (1994). The Language Instinct. Penguin.

Potts, Christopher (2007). The Expressive Dimension. Theoretical Linguistics, 33(2), 165-198.

Pushkin, Aleksandr Sergeevich (1828/1959). Ty i vy: ("Pustoe vy serdechnym ty ..."). In Stikhotvoreniya 1823-1836 (207), Vol. 2 of Sobranie sochinenii $v$ 10 
tomakh. Gosudarstvennoe Izdatel'stvo Khudozhestvennoi Literaturoi 19591962.

Pushkin, Aleksandr Sergeevich (1828/1999). Thou and You. In Lyric Poems 1826-1836 (75), Vol. 3 of The Complete Works of Alexander Pushkin. Milner.

Richard, Mark (2008). When Truth Gives Out. Oxford University Press.

Sankoff, Gillian (2001). Linguistic Outcomes of Language Contact. In Peter Trudgill, J. Chambers, and N. Shilling-Estes (Eds.), Handbook of Sociolinguistics (638-668). Basil Blackwell.

Scheffler, Samuel (2007). Immigration and the Significance of Culture. Philosophy and Public Affairs, 35(2), 93-125.

Searle, John (1975). A Taxonomy of Illocutionary Acts. In Keith Gunderson (Ed.), Language, Mind, and Knowledge (344-369). University of Minnesota Press.

Stainton, Robert (2016). Full-On Stating. Mind and Language, 31(4), 395-413.

Taylor, Charles (1994). The Politics of Recognition. In Amy Gutmann (Ed.), Multiculturalism: Examining the Politics of Recognition (25-74). Princeton University Press.

Van Parijs, Philippe (2000). The Ground Floor of the World: On the SocioEconomic Consequences of Linguistic Globalization. International Political Science Review, 21(2), 217-233.

Van Parijs, Philippe (2003). Linguistic Justice. In Alan Patten and Will Kymlicka (Eds.), Language Rights and Political Theory (153-168). Oxford University Press. Waldron, Jeremy (1991). Minority Cultures and the Cosmopolitan Alternative. University of Michigan Journal of Law Reform, 25(4), 751-793.

Whorf, Benjamin Lee (1956). Language, Mind, and Reality. In John B. Carroll (Ed.), Language, Thought, and Reality (246-270). Technology Press of MIT. 